\title{
CURB-65 versus APACHE II as a Prognostic Score to Assess Severity of Sepsis in Critically Ill Geriatric Patients
}

\author{
DIAA ELDIEN M. HAIBA, M.D.; HATEM S. ABDEL HAMID, M.D.; SHERIF Y. MAHMOUD, M.Sc. and \\ ENGY S. ATTYA, M.D.
}

The Department of Anesthesiology, Intensive Care and Pain Management, Faculty of Medicine, Ain Shams University

\begin{abstract}
Background: Sepsis is a complex condition defined by the systemic response to infection. Severity assessment scoring systems are used to aid the physician in deciding whether aggressive treatment is needed or not. In this study, two severity assessment scoring systems, namely Acute Physiology and Chronic Health Evaluation II (APACHE II) and CURB65 were compared to assess their sensitivity and specificity.

Aim of Study: To compare the efficacy between CURB65 and APACHE II in assessment of the severity of sepsis and predicting mortality in critically ill geriatric patients.

Patients and Methods: This prospective comparative study was conducted on patients admitted at Critical Care department of Ain Shams University Hospitals, Cairo, Egypt, for 3 months duration. Patients admitted to the general ICU of Ain Shams University Hospitals with sepsis or septic shock of both sexes

Results: The simplicity of calculation of CURB65 demonstrated superiority over other complex severity scores utilized in crowded emergency rooms. Furthermore, the CRB65 score, which does not require a blood urea level, is more suitable for use in gross-roots hospitals. In the current study, CURB-65 score was statistically significantly higher in the non-survivors as compared with the survivors $(1.79 \pm 1.26$ and $0.65 \pm 0.43$ respectively) $(p<0.001)$. Moreover, in our study, the cutoff point of Curb-65 score to differentiate between non-survivors from survivors was $>2$ with $59 \%$ sensitivity and $92.3 \%$ specificity. Unfortunately, no much data is available to describe the prognostic ability of CURB65 in patients with sepsis, as the score was originally developed to assess the prognosis in pneumonia patients.
\end{abstract}

Conclusion: Sepsis is a life threating condition and is one of the leading causes of death. Mortality was reported in $55.7 \%$ of patients by the end of the study period. APACHE II was predicting mortality with $84.6 \%$ sensitivity and $64.5 \%$ specificity, $78.8 \%$ PPV \& $86.4 \%$ NPV and $82.2 \%$ accuracy. The length of hospital stay was significantly longer in nonsurvivor group. CURB-65 was statically significantly higher in the non-survivors as compared with the survivors with 59\% sensitivity and $92.3 \%$ specificity but no much data available to describe prognostic ability of CURB-65 in-patient with sepsis as in pneumonia patients.

Correspondence to: Dr. Sherif Y. Ibrahim, E-Mail: sherifyoussef71@gmail.com
Key Words: Glasgow coma scale - White blood cell countIntensive care unit.

\section{Introduction}

SEPSIS is a life-threatening condition and is one of the leading causes of death. New definitions for sepsis and septic shock (sepsis-3) were published [1].

Sepsis is now defined as life-threatening organ dysfunction caused by a dysregulated host response to infection. Septic shock is a subset of sepsis with circulatory and cellular/metabolic dysfunction associated with a higher risk of mortality. Mortality from septic shock in the intensive care unit (ICU) is estimated to range between $45 \%$ and $63 \%$ in observational studies [2].

Severity assessment scoring systems are used to triage the patients presenting with sepsis to aid the physician in deciding whether aggressive treatment is needed. This can save time, cost for the patient, and ensure that he receives adequate care.

Different scoring systems have been introduced to determine the disease severity and prognosis of patients admitted in the ICU [4]

The objective of our study is to compare severity assessment between two scoring systems, namely the Acute Physiology, Age and Chronic Health Evaluation II (APACHE II) and CURB-65.

APACHE II is a computer-based ICU scoring system points from 0 to 71 based on patient's age, oxygen partial pressure $(\mathrm{PaO} 2)$, body temperature, mean arterial pressure, arterial $\mathrm{pH}$, heart rate, respiratory rate, serum sodium, serum potassium, creatinine, hematocrit, white blood cell count (WCC), and Glasgow Coma Scale (GCS). It is applied within $24 \mathrm{~h}$ of admission to ICU to describe 
patients' morbidity, assess the disease severity, and mortality risk. The higher APACHE II score reflects disease severity and increased mortality in ICU patients with sepsis [5]

The new score tool CURB-65. One point for each (confusion, urea $>7 \mathrm{mmol} / \mathrm{L}$, respiratory rate $>30 / \mathrm{min}$, blood pressure $<90 / 60 \mathrm{mmHg}$, and age $>65$ years).

CURB-65 can predict mortality with an overall sensitivity and specificity of about $80 \%$ and helps in the stratification of patients in three management groups with CURB-65 score of 0-1, 2, and $>2$ as low risk (mortality $<2 \%$ ) for outpatient management, intermediate risk (mortality 9\%) for hospital supervised treatment, and high risk (mortality $>19 \%$ ) treated initially in an intensive care or high dependency unit, respectively [6]

Aim of the work:

The aim of this study is to compare the efficacy between CURB-65 and APACHE II in assessment of the severity of sepsis and predicting mortality in critically ill geriatric patients.

\section{Patients and Methods}

This prospective comparative study was conducted on patients admitted at Critical Care department of Ain Shams University Hospitals, Cairo, Egypt, during the period from the beginning of October 2020 to the end of December 2020.

Inclusion criteria: Patients admitted to the general ICU of Ain Shams University Hospitals with sepsis or septic shock of both sexes.

Exclusion criteria: A lack of informed consent. Systemic chronic diseases (renal failure, liver failure, hematologic diseases, neutropenia, malignancy). Chemotherapy during the previous 90 days.

Patients were divided into two groups, CURB65 score assessed group A for patients as a prognostic score and APACHE II score assessed group $\mathrm{B}$ for patients as a prognostic score.

Defining: For all patients According to Third International Consensus Definitions for Sepsis and Septic Shock (Sepsis-3) [7]. Adult patients with suspected infection are identified, having quick SOFA (qSOFA) score meeting > 2 of the following criteria: Respiratory rate of $22 / \mathrm{min}$ or greater. Altered mentation, or Systolic blood pressure of $100 \mathrm{mmHg}$ or less [7].

Sepsis is defined as life-threatening organ dysfunction caused by a dysregulated host response to infection. Organ dysfunction can be identified as an acute change in total SOFA score 2 points subsequent to the infection. Septic shock is defined as sepsis patient who have persistent hypotension that requires vasopressors to maintain a MAP $>65 \mathrm{mmHg}$ and who have a serum lactate level $>2 \mathrm{mmol} / \mathrm{L}$ despite adequate volume resuscitation.

\section{Patients consent:}

A written informed consent was obtained from all the patients (or their guardians if unconscious) before inclusion in the study, explaining the value of the study, plus the procedures that were commenced.

Ethical consideration: The Ethics Committee, Faculty of Medicine, Ain-Shams University, approved the whole study design. Confidentiality and personal privacy were respected in all levels of the study. Guardians felt free to withdraw from the study at any time without any consequences. Collected data was not and will not be used for any other purpose.

\section{Methodology:}

Data collection and recording:

On admission, the following was done and recorded for all participants (to be repeated when appropriate): Detailed medical history; including history of previous ICU admission, associated comorbidities and reason of ICU admission. Full general and local chest clinical examination. Need for vasoactive therapy, fluid balance and need for renal replacement therapy.

Laboratory investigations: Complete blood picture (CBC). Arterial blood gases analysis (AB$\mathrm{Gs}$ ) on a daily basis. Serum Sodium (Na) and Potassium (K). Liver and Kidney function tests. Serum lactate (repeated when needed to fulfill criteria for diagnosis of septic shock).

Radiological investigations: Chest X-ray (CXR). CT chest or brain (when appropriate).

\section{Microbiological samples culture and sensitivity (when appropriate):}

Sputum, urine, pleural fluid, or from infected IV line according to the suspected site. Type of infection (community or hospital acquired), infection site: (Lungs, urinary tract, abdomen, surgical wound), pathogenic organisms (gram positive, gram negative, atypical bacteria and fungi) were recorded.

\section{Neurological state assessment:}

Glasgow Coma Scale (GCS) (Table 1). Quick Sepsis Related Organ Failure Assessment (qSOFA) 
score (Table 10) was recorded at emergency room. Sequential Organ Failure Assessment (SOFA) score (Table 11) was recorded upon RICU admission and on 3 rd and 7 th days. Acute Physiology and Chronic Health Evaluation (APACHE II) score (Table 12) was recorded within 24 hours from patient RICU admission Assessment of the CURB65 (Table 13).

All patients were subjected to the following management protocol regarding the recent Surviving Sepsis Campaign Bundle Update [8]:

Measuring lactate level with serial measurement if it was more than $2 \mathrm{mmol} / \mathrm{L}$ Blood culture prior to antibiotic administration. Broad-spectrum antibiotics directly after blood culture aspiration; begun with mono broad-spectrum; carbapenems or penicillin/0-lactamase inhibitor; recommended as first choice drugs. Patients with a high risk of mortality such as septic shock received a combination therapy with at least two different classes of antibiotics depending on type of organism, source of infection, choosing of antibiotics kept in mind the most organisms isolated from septic patients. Early fluid resuscitation using $30 \mathrm{~mL} / \mathrm{Kg}$ crystalloid fluid was given for cases of hypotension or when lactate level $>4 \mathrm{mmol} / \mathrm{L}$. Perfusion assessment using CVP and central venues oxygen saturation. Vasopressor use (norepinephrine was given) for persistent hypotension to maintain MAP more than or equal $65 \mathrm{mmHg}$. Adjunctive therapy with steroids (200mg IV hydrocortisone/day) was given in patients with sepsis who remain hemodynamically unstable despite adequate fluid resuscitation and vasopressor therapy. Glycemic control was done when patient blood glucose level exceeded $180 \mathrm{mg} / \mathrm{dL}$ by administrating insulin.

APACHE II is a computer-based ICU scoring system points from 0 to 71 based on patient's age, oxygen partial pressure $(\mathrm{PaO} 2)$, body temperature, mean arterial pressure, arterial $\mathrm{pH}$, heart rate, respiratory rate, serum sodium, serum potassium, creatinine, hematocrit, white blood cell count (WCC), and Glasgow Coma Scale (GCS). It is applied within $24 \mathrm{~h}$ of admission to ICU to describe patients' morbidity, assess the disease severity, and mortality risk. The higher APACHE II score reflects disease severity and increased mortality in ICU patients with sepsis [5]

The new score tool CURB-65. One point for each (confusion, urea $>7 \mathrm{mmol} / \mathrm{L}$, respiratory rate $>30 / \mathrm{min}$, blood pressure $<90 / 60 \mathrm{mmHg}$, and age $>65$ years).
CURB-65 canpredict mortality with an overall sensitivity and specificity of about $80 \%$ and helps in the stratification of patients in three management groups with CURB-65 score of 0-1, 2, and $>2$ as low risk (mortality $<2 \%$ ) for outpatient management, intermediate risk (mortality $9 \%$ ) for hospital supervised treatment, and high risk (mortality $>19 \%$ ) treated initially in an intensive care or high dependency unit, respectively [6].

Outcome measured: The primary outcome was mortality during the first 7 days of admission at intensive care. Secondary outcome measures: ICU length of stay. Need for any of the following supportive measures: Ventilatory support duration.

\section{Statistical analysis and data interpretation:}

Data were fed to the computer and analyzed using IBM SPSS software package version 22.0. Qualitative data were described using number and percent. Quantitative data were described using median (minimum and maximum) for non-parametric data and mean, standard deviation for parametric data after testing normality using Kolmogrov-Smirnov test. Significance of the obtained results was judged at the (0.05) level.

\section{Data analysis qualitative data:}

Chi-Square test for comparison of 2 or more groups. Monte Carlo test as correction for ChiSquare test when more than $25 \%$ of cells have count less than 5 in tables $(>2 * 2)$. Fischer Exact test was used as correction for Chi-Square test when more than $25 \%$ of cells have count less than 5 in $2 * 2$ tables.

\section{Quantitative data between two groups:}

Parametric tests: Student $t$-test was used to compare two independent groups.

Non-Parametric tests: Mann-Whitney U test was used to compare two independent groups.

\section{Diagnostic accuracy:}

Receiver Operating Characteristic (ROC) curve analysis:

The diagnostic performance of a test or the accuracy of a test to discriminate diseased cases from non-diseased cases is evaluated using Receiver Operating.

Characteristic (ROC) curve analysis. Sensitivity and Specificity were detected from the curve and PPV, NPV and accuracy were calculated through cross tabulation.

For all the above-mentioned tests, the level of significance was tested, expressed as the probability 
of ( $p$-value) and the results were explained as following: Non-significant if the $p$-value is $>0.05$. Significant if the $p$-value is $\leq 0.05$. Highly significant if the $p$-value $<0.001$.

\section{Results}

Table (1): Demographic data in the two studied groups.

\begin{tabular}{cc}
\hline Items & $\begin{array}{c}\text { Study cases } \\
\mathrm{n}=70\end{array}$ \\
\hline Age (years): & \\
Mean \pm SD & $67.43 \pm 9.58$ \\
Median (min-max) & $68(45-87)$ \\
Sex: & \\
Male & $41(58.6 \%)$ \\
Female & $29(41.4 \%)$
\end{tabular}

Continuous data expressed as mean $\pm \mathrm{SD}$ and median (range)

Categorical data expressed as Number $(\%)$.

Table (2): Clinical data in the two studied groups.

\begin{tabular}{ll}
\hline Items & $\begin{array}{c}\text { Study cases } \\
\mathrm{n}=70\end{array}$ \\
\hline Source of infection: & \\
Chest infection & $36(51.4 \%)$ \\
UTI & $25(35.7 \%)$ \\
Skin and soft tissue & $17(24.3 \%)$ \\
Intraabdominal & $13(18.6 \%)$ \\
Blood stream & $8(11.4 \%)$ \\
Associated chronic diseases: & \\
Diabetic & $53(75.7 \%)$ \\
HTN & $42(60 \%)$ \\
IHD & $29(41.4 \%)$ \\
CKD & $16(22.9 \%)$ \\
COPD & $14(20 \%)$ \\
\hline
\end{tabular}

Continuous data expressed as mean \pm SD and median (range).

Categorical data expressed as Number (\%).

Table (3): Outcome in the two studied groups.

\begin{tabular}{cc}
\hline Items & $\begin{array}{c}\text { Study cases } \\
\mathrm{n}=70\end{array}$ \\
\hline Length of hospital stay (days): & $7(4-19)$ \\
Survival & $39 \stackrel{(55.7 \%)}{\text { Died }}$ \\
Survived & $31(44.3 \%)$ \\
\hline
\end{tabular}

Table (4): Demographic data in the study cases according to survival.

\begin{tabular}{|c|c|c|c|}
\hline Items & $\begin{array}{c}\text { Group I } \\
\text { (Non-survivors) } \\
n=39\end{array}$ & $\begin{array}{c}\text { Group II } \\
\text { (Survivors) } \\
n=31\end{array}$ & $\begin{array}{c}p- \\
\text { value }\end{array}$ \\
\hline Age (years) & $57.93 \pm 8.67$ & $51.13 \pm 4.61$ & $0.015 *$ \\
\hline $\begin{array}{l}\text { Sex: } \\
\quad \text { Male } \\
\\
\text { Female }\end{array}$ & $\begin{array}{l}25(64.1 \%) \\
14(35.9 \%)\end{array}$ & $\begin{array}{l}16(51.6 \%) \\
15(48.4 \%)\end{array}$ & 0.163 \\
\hline $\begin{array}{l}\text { Height }(\mathrm{cm}) \\
\text { Weight }(\mathrm{kg})_{2} \\
\text { BMI }(\mathrm{kg} / \mathrm{m})^{2}\end{array}$ & $\begin{array}{l}168.16 \pm 7.12 \\
85.98 \pm 10.96 \\
30.35 \pm 3.89\end{array}$ & $\begin{array}{l}168.47 \pm 8.26 \\
84.96 \pm 14.46 \\
29.83 \pm 4.46\end{array}$ & $\begin{array}{l}0.849 \\
0.706 \\
0.552\end{array}$ \\
\hline
\end{tabular}

Table (5): Source of infection and associated chronic diseases between survivors and non survivors.

\begin{tabular}{llllll}
\hline & $\begin{array}{c}\text { Group I } \\
\text { (Non-survivors) } \\
\mathrm{n}=39\end{array}$ & $\begin{array}{c}\text { Group II } \\
\text { (Survivors) } \\
\mathrm{n}=31\end{array}$ & $\begin{array}{c}p \text { - } \\
\text { value }\end{array}$ \\
\hline $\begin{array}{l}\text { Source of infection: } \\
\quad \text { Chest infection }\end{array}$ & 22 & $56.4 \%$ & 14 & $45.2 \%$ & 0.063 \\
$\quad$ UTI & 12 & $30.8 \%$ & 13 & $41.9 \%$ & 0.065 \\
$\quad$ Skin and soft tissue & 8 & $20.5 \%$ & 9 & $29.1 \%$ & 0.104 \\
$\quad$ Intraabdominal & 7 & $17.9 \%$ & 6 & $19.3 \%$ & 0.746 \\
$\quad$ Blood stream & 5 & $12.8 \%$ & 3 & $9.7 \%$ & 0.270 \\
Associated chronic & & & & & \\
diseases: & & & & & \\
$\quad$ Diabetic & 29 & $74.4 \%$ & 24 & $77.4 \%$ & 0.286 \\
HTN & 25 & $64.1 \%$ & 17 & $54.8 \%$ & 0.087 \\
IHD & 16 & $41.2 \%$ & 13 & $41.9 \%$ & 0.876 \\
CKD & 9 & $23.1 \%$ & 7 & $22.5 \%$ & 0.724 \\
COPD & 7 & $17.9 \%$ & 7 & $22.5 \%$ & 0.158 \\
\hline
\end{tabular}

$p_{2}$ Probability. Categorical data are expressed as number $(\%)$. $\chi=$ Chi-square test.

Table (6): Analysis of items of general examination in the two study groups.

\begin{tabular}{|c|c|c|c|}
\hline & $\begin{array}{c}\text { Group I } \\
\text { (Non-survivors) } \\
n=39\end{array}$ & $\begin{array}{c}\text { Group II } \\
\text { (Survivors) } \\
\mathrm{n}=31\end{array}$ & $\begin{array}{c}p- \\
\text { value }\end{array}$ \\
\hline GCS & $10(3-14)$ & $13(8-15)$ & $0.016 *$ \\
\hline Pulse (B/Min) & $121.05 \pm 12.36$ & $107.93 \pm 9.06$ & $0.002 *$ \\
\hline MAP (mmHg) & $64.33 \pm 15.68$ & $61.64 \pm 13.09$ & 0.362 \\
\hline RR (Cycle/Min) & $23(15-34)$ & $22(14-31)$ & 0.127 \\
\hline Temperature $\left({ }^{\circ} \mathrm{C}\right)$ & $39.09 \pm 2.98$ & $38.46 \pm 3.23$ & 0.068 \\
\hline APACHE score & $22.95 \pm 3.23$ & $14.51 \pm 2.64$ & $<0.001 *$ \\
\hline Predicted death rate & $52.3 \pm 23.3$ & $41.58 \pm 20.6$ & $<0.001 *$ \\
\hline CURB-65 score & $1.79 \pm 1.26$ & $0.65 \pm 0.43$ & $<0.001 *$ \\
\hline SOFA score & $4.23 \pm 2.26$ & $1.95 \pm 1.02$ & $<0.001 *$ \\
\hline
\end{tabular}

Data are expressed as Median (Min-Max) or Mean \pm SD.

$p$ : Probability. $\quad *$ : Statistically significant $(p<0.05)$.

Table (7): Analysis of laboratory parameters in the two study groups.

\begin{tabular}{|c|c|c|c|}
\hline & $\begin{array}{c}\text { Group I } \\
\text { (Non-survivors) } \\
\mathrm{n}=39 \\
\end{array}$ & $\begin{array}{c}\text { Group II } \\
\text { (Survivors) } \\
\mathrm{n}=31 \\
\end{array}$ & $\begin{array}{c}p- \\
\text { value }\end{array}$ \\
\hline $\operatorname{ESR}(\mathrm{mm} / \mathrm{h})$ & $36(20-76)$ & $13(10-18)$ & $0.001 *$ \\
\hline CRP & $116.70 \pm 22.53$ & $49.41 \pm 12.62$ & $<0.0001 *$ \\
\hline $\operatorname{RBCs}\left(10^{6} / \mathrm{ml}\right)$ & $4.03 \pm 0.60$ & $4.91 \pm 0.58$ & 0.154 \\
\hline PLTs $\left(10^{6} / \mathrm{ml}\right)$ & $418(382-452)$ & $259(145-442)$ & $<0.001 *$ \\
\hline WBCs $\left(10^{6} / \mathrm{ml}\right)$ & $19.14 \pm 2.98$ & $16.24 \pm 2.07$ & 0.142 \\
\hline $\begin{array}{l}\text { GFR }(\mathrm{ml} / \mathrm{min} / \\
\left.1.73 \mathrm{~m}^{2}\right)\end{array}$ & $58(40-80)$ & $89(55-127)$ & $0.004^{*}$ \\
\hline BUN & $31.53 \pm 11.25$ & $12.25 \pm 3.89$ & $<0.001 *$ \\
\hline $\begin{array}{l}\text { Serum urea } \\
(\mathrm{mg} / \mathrm{dl})\end{array}$ & $74.06 \pm 23.29$ & $23.66 \pm 6.74$ & $<0.001 *$ \\
\hline $\begin{array}{l}\text { Serum creatinine } \\
(\mathrm{mg} / \mathrm{dl})\end{array}$ & $1.96 \pm 0.65$ & $0.73 \pm 0.20$ & $<0.001 *$ \\
\hline $24 \mathrm{H}$ protein $(\mathrm{mg})$ & $917.64 \pm 243.67$ & $286.51 \pm 23.64$ & $<0.001 *$ \\
\hline
\end{tabular}


Table (8): Analysis of laboratory parameters in the two study groups (continuation).

\begin{tabular}{llll}
\hline & \multicolumn{1}{c}{$\begin{array}{c}\text { Group I } \\
\text { (Non-survivors) } \\
\mathrm{n}=39\end{array}$} & $\begin{array}{c}\text { Group II } \\
(\text { Survivors }) \\
\mathrm{n}=31\end{array}$ & $\begin{array}{c}p \text { - } \\
\text { value }\end{array}$ \\
\hline $\begin{array}{l}\text { Positive blood } \\
\quad \text { culture }\end{array}$ & $20(57.1 \%)$ & $15(23.1 \%)$ & $0.002^{*}$ \\
Anion gap & $10(8-13)$ & $12(9-15)$ & 0.365 \\
$\mathrm{PH}$ & $7.31(7.18-7.34)$ & $7.35(7.27-7.4)$ & $0.046^{*}$ \\
$\mathrm{PaO} 2$ & $88.5(70-116)$ & $89.5(69-116)$ & 0.217 \\
$\mathrm{FiO} 2(\%)$ & $23(17-31)$ & $25(18-30)$ & 0.108 \\
$\mathrm{PCO} 2$ & $43.2(34-52)$ & $42(35-49)$ & 0.164 \\
$\mathrm{~K}$ & $4.2 \pm 1.12$ & $4.9 \pm 1.51$ & $0.004^{*}$ \\
$\mathrm{Serum} \mathrm{lactate}$ & $3.92 \pm 0.90$ & $1.78 \pm 0.17$ & $<0.001 *$ \\
$\quad(\mathrm{mmol} / \mathrm{L})$ & & & \\
Initial BD & $10.4 \pm 2.76$ & $8.87 \pm 1.52$ & $0.019^{*}$ \\
$\quad(\mathrm{mEq} / \mathrm{L})$ & & & \\
\hline
\end{tabular}

Data are expressed as Median (Min-Max) or Mean \pm SD

$p$ : Probability.

*: Statistically significant $(p<0.05)$

Table (9): Analysis of outcome variables in the two studied groups.

\begin{tabular}{lccc}
\hline & $\begin{array}{c}\text { Group I } \\
\text { (Non-survivors) } \\
\mathrm{n}=39\end{array}$ & $\begin{array}{c}\text { Group II } \\
\text { (Survivors) } \\
\mathrm{n}=31\end{array}$ & $\begin{array}{c}p \text { - } \\
\text { value }\end{array}$ \\
\hline $\begin{array}{l}\text { Length of ICU stay } \\
\begin{array}{l}\text { Requirement for } \\
\text { mechanical } \\
\text { ventilation }\end{array}\end{array}$ & $28(6-19)$ & $5(4-12)$ & $<0.001 *$ \\
\hline
\end{tabular}

Data are expressed as Median (Min-Max) or Mean \pm SD.

$p$ : Probability.

*: Statistically significant $(p<0.05)$.

Table (10): Predictive ability of Curb-65 score and APACHE II score in prediction of mortality among the cases.

\begin{tabular}{lll}
\hline & Curb-65 score & APACHE II score \\
\hline AUC & 0.759 & 0.840 \\
95\% CI of AUC & $0.668-0.889$ & $0.714-0.912$ \\
Cut off point & $>2$ & $>17$ \\
Sensitivity & $59 \%$ & $\mathbf{8 4 . 6 \%}$ \\
Specificity & $92.3 \%$ & $\mathbf{6 4 . 5 \%}$ \\
Accuracy & $\mathbf{7 6 . 4 \%}$ & $82.8 \%$ \\
PPV & $90.4 \%$ & $78.8 \%$ \\
NPV & $\mathbf{8 2 . 2 \%}$ & $86.4 \%$ \\
$p$ & $<0.001 *$ & $<0.001 *$ \\
\hline
\end{tabular}

AUC : Area under curve.

CI : Confidence interval.

PPV : Positive predictive value.

NPV : Negative predictive value.

$p \quad$ : Probability value.

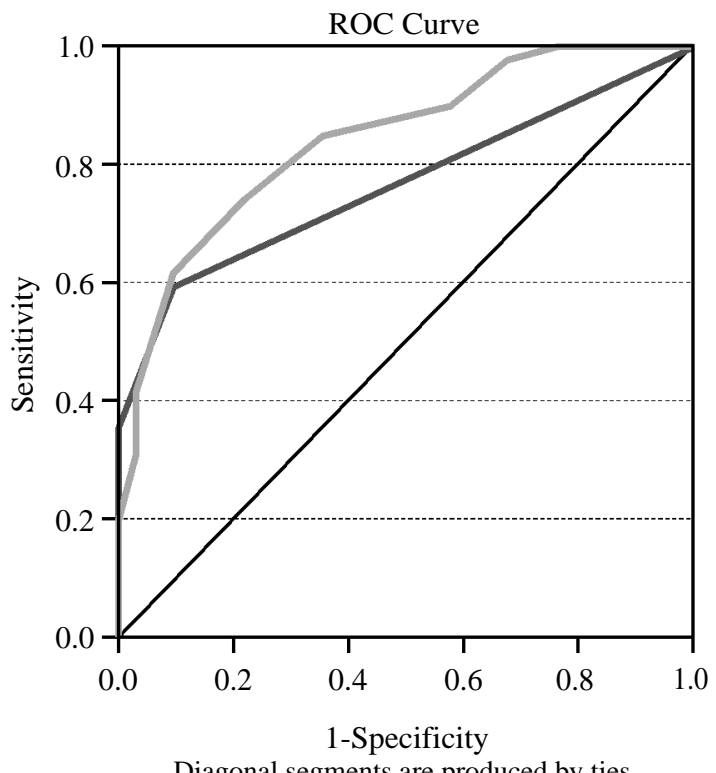

Diagonal segments are produced by ties

$$
\begin{aligned}
& \text { Source of the curve } \\
& \text { CURB_65_Score } \\
& \text { APACHE II } \\
& \text { Reference Line }
\end{aligned}
$$

Fig. (1): ROC curve for Curb-65 score and APACHE II score in prediction of mortality among the cases.

Table (11): Univariate and multivariate regression analysis of risk of mortality $(n=39)$.

\begin{tabular}{llccc}
\hline & & \multicolumn{3}{c}{ Multivariate analysis } \\
\cline { 3 - 5 } Variables & $\begin{array}{c}\text { Univariate } \\
\text { analysis }\end{array}$ & OR & $\begin{array}{c}95 \% \text { CI } \\
\text { for OR }\end{array}$ & $\begin{array}{c}p \text { - } \\
\text { value }\end{array}$ \\
\hline Age & 0.136 & & & \\
Sex & 0.273 & & & \\
HTN & 0.359 & & & \\
DM & 0.655 & & & \\
GCS & $0.019 *$ & 0.377 & $0.075-1.909$ & 0.183 \\
RR & 0.125 & & & \\
PH & 0.267 & & & \\
Platelets count & 0.453 & & & \\
WBCs count & 0.896 & & & \\
BUN & 0.567 & & & \\
GFR & 0.452 & & & \\
Serum creatinine & 0.425 & & & \\
Lactate & $0.012 *$ & 1.113 & $0.937-1.332$ & 0.211 \\
SOFA score & $0.029 *$ & 0.849 & $0.684-1.113$ & 0.242 \\
Curb-65 score & $0.005^{*}$ & 1.182 & $1.004-1.954$ & $0.041 *$ \\
APACHE II score & $<0.001 *$ & 1.546 & $1.215-2.642$ & $0.009 *$ \\
\hline
\end{tabular}

OR : Odd's ratio.

CI : Confidence interval.

: Statistically significant $(p<0.05)$ 


\section{Discussion}

Sepsis and septic shock are one of the leading causes of death worldwide. According to data from the Centers for Disease Control and Prevention, sepsis is the leading cause of death in non-coronary ICU patients [10].

Severity of illness and mortality risk escalates with severity of organ dysfunction. Severe sepsis and septic shock carry high potential mortality rates, possibly up to $40 \%-50 \%$ [11].

Prognostication in severe sepsis may facilitate aggressive management of particular patient groups. Prognostic factors such as age, sex, comorbidities, biomarkers (C-reactive protein [CRP], procalcitonin, etc.), and severity of illness score (Acute Physiology and Chronic Health Evaluation [APACHE], etc.,) have been reported to be associated with the outcome in cases of severe sepsis $[\mathbf{1 2 , 1 3 , 1 4 ]}$.

Although these systems are considered to diagnose sepsis, in fact they have been developed to ensure the prediction of patients at high risk among the ones with suspected infection. Apart from these, there are systems that can predict mortality of patients. These early warning scores have been developed for early detection of patients at risk of mortality and can be simply performed by bedside and primarily with physiologic parameters [15]

This study was conducted at Ain-Shams University Hospitals aiming to compare the efficacy between CURB-65 and APACHE II in assessment of the severity of sepsis and predicting mortality in critically ill geriatric patients.

The study included 70 cases with their mean age of 67.43 years (range, 45-87). Regarding gender, there were 41 males $(58.6 \%)$ and 29 females (41.4\%). Out of the included 70 cases, mortality encountered in 39 cases with incidence of $55.7 \%$.

The mortality rate in our study was similar to that reported by Hassan et al., at Assiut University where the mortality rate was $64.7 \%$ [16]. However, it was higher than that reported by another Egyptian study (39\%) [17].

Another study handling the same perspective included 124 cases, from whom 88 cases $(70.9 \%)$ were non-survivors [18]. Another study included 301 cases, 102 cases in the non-survivor group (33.8\%), and 199 cases in the survivor group [19]

From the researcher's point of view, the difference in the mortality rates could be explained due to variations in the inclusion and exclusion criteria between the different studies.

It is known that the mortality rates increased with the severity of sepsis due to the acute circulatory failure and the multiple organs dysfunction associated with the septic shock that are profound enough to substantially increase the death rate [2]

In our study, the mean age of the cases in the non-survivor group was $57.93 \pm 8.67$ years and in the survivor group was $51.13 \pm 4.61$ years with a statistically significant difference between the two groups $(p=0.015)$.

In agreement with our results, Kim et al. [20] showed higher ages in the non-survivor group 78 years (73.8-83) with male percentage of $52.8 \%$.

Orak and his colleagues reported that age was also significantly older in the deceased group (67.78 vs. 52.94 years $-p<0.001)$ [21]. This result comes in line with our study results.

Angus et al., found that there is a direct relationship between advanced age and the incidence of mortality in septic patients with a marked increase in incidence in elderly individuals [22]

Conversely, another study reported no significant difference between the survivor and nonsurvivor groups (61.17 vs. $61.70-p=0.82)$ [18]

The difference could be explained due to the different sample size between the studies. Also, the increased life expectancy in some communities is associated with increasing age either in survivors and non-survivors.

When it comes to gender distribution in the current study, there were 25 males $(64.1 \%)$ and 14 females $(35.9 \%)$ in the non-survivor group and 16 $(51.6 \%)$ males and $15(48.4 \%)$ females in the survivor group with no statistically significant difference between the two groups.

Choi and his associates also reported that no statistically significant difference was found regarding gender distribution in their study ( $p=0.796)$. Male sex constituted 61.3 and $66.7 \%$ of the survivor and non-survivor groups respectively.

In agreement with our results, Kim et al., [20] showed higher ages in the non-survivor group 78 years (73.8-83) with male percentage of $52.8 \%$.

However, in contrast to our results, in another study, male sex was more predominant in the nonsurvivor group ( $71.4 \%$ vs. $46.5 \%$ in the survivors - $p=0.005)$ [23] 
Regarding the cause of sepsis, it did not differ significantly between the two groups in the current study. Chest infection was the commonest source of sepsis in both study groups (56.4\% and $45.2 \%)$, followed by UTI (30.8\% and $41.9 \%)$.

Like our study, GAO and his colleagues reported that the primary infectious focus did not differ between the two groups $(p>0.05)$. Pulmonary infections were the commonest in both groups $(44.4 \%$ and $63.63 \%$ respectively), followed by intraabdominal infections (38.89\% and 26.14\%) [18].

In partial agreement with our findings, Kim and his colleagues reported that there was a significant difference regarding the main site of infection. Although they differ in the level of significance, there were that pneumonia was the commonest cause in non survivors $(45.7 \%)$ while UTI was the commonest source in survivors (27.4\%) [23].

When it comes to comorbidities in our study cases, no statistically significant difference was present between the two groups. Diabetes and hypertension was the commonest between both groups.

In another study, both diabetes mellitus and hypertension were not significantly different between the study groups. Diabetes was present in 30.5 and $22.5 \%$ in survivors and non-survivors group respectively $(p=0.264)$. Regarding hypertension, it was present in $58.7 \%$ and $57.5 \%$ in both groups respectively ( $p=969)$ [24].

Orak et al., reported that diabetes and hypertension had a higher prevalence in the nonsurvivors. Diabetes was present in $43.3 \%$ and $28.8 \%$ of cases in non-survivors and survivors groups respectively ( $p=0.012$ ). Moreover, hypertension was present in $20.1 \%$ of non-survivor group cases, and only 7.2 of survivors ( $p=0.002)$. Nevertheless, chronic kidney disease and COPD did not differ significantly between both groups ( $p=0.189$ and 0.10 respectively) [21].

In the current study, by comparing the different items of the initial clinical examination within the two groups, the MAP, RR and temperature didn't reveal any significant difference between the two groups, however the median GCS in the survivor group was significantly higher than the nonsurvivor group $(p=0.016)$.

In line with our study, Kim et al., reported that the mean arterial blood pressure did not differ between the two groups [23]
In addition, our results came in accordance with Jandial et al., who showed statistically significant difference between the two study groups (survived vs non-survived group) regarding RR and GCS at admission [25].

Our results agreed with Kim et al., who showed that the mean arterial pressure and mean HR didn't reveal any statistically significant difference between the two study groups in their study [20].

Our results partially came in agreement with Shaikh and Yadavalli [10] who showed that the mean heart rate, and respiratory rate was higher among non-survivors, Mean systolic blood and diastolic blood pressures were lower among nonsurvivors when compared to controls [10]

Another study reported that respiratory rate ( 26.0 vs. $28.3-p=0.028$ ) was significantly higher in the non-survivors. The same study reported that no significant difference was present regarding mean arterial pressure, body temperature or oxygen saturation ( $p=0.465,0.629$, and 0.498 respectively). Moreover, heart rate was significantly different between the study groups, but it was higher in the survivors. This contradicts with our study results [24].

In the current study, non-survivor group expressed significantly higher values for APACHE score $(22.95 \pm 3.23$ vs. $14.51 \pm 2.64)$ ( $p$-value $<0.001)$. Moreover, predicted death rate and SOFA score were statistically significantly higher in the non-survivors $(p<0.001)$.

In line with our study, et al., reported that APACHE score was significantly higher in the non-survivors $(25.9$ vs. $16.5-p<0.001)$ [23].

This came in agreement with Saad et al., who showed that the mean APACHE II score in the non-survived patients was $99.1 \pm 31.03$ which was significantly higher as compared with the survived group (67.7 \pm 18.86$)(p=0.001)$ [26] .

This agreed with Salem et al., who showed that APACHE II score was $22 \pm 2.9$ and $23.5 \pm 4$ in survivors and non-survivors respectively with statistically significant difference between the two groups $(p=0.005)$. The mean SOFA score was $9.6 \pm 1.8$ and $10.5 \pm 2.2$ in survivors and nonsurvivors respectively with statistically significant difference between the two groups $(p=0.005)$ [27]

In line with these data, Jiang et al., found APACHE II score in patients with sepsis, and reflected disease severity [28]. In addition, Huang et al., documented that APACHE II scores on 
postoperative day- 1 were the variables significantly associated with sepsis and its severity [29]. Recently, Qiu et al., reported that APACHE IIshowed an increasing trend with the increase in infection severity in ICU patients [30].

Multiple recent studies assured that among variables registered on day 1 , APACHE II and SOFA scores were independently associated with sepsis severity and 28-MR [31,32]

The CRP is one of non-specific acute phase reactants used in clinical practice to aid in the diagnosis and management of infection. However, these acute phase reactants rise indiscriminately in response to any inflammation even without bacterial infection $[33,34]$.

In the current study, CRP levels were significantly higher in the non-survivors as compared with the survivors $(116.70 \pm 22.53 \mathrm{vs} .49 .41 \pm$ $12.62 \mathrm{mg} / \mathrm{dl} p<0.0001)$.

We agreed with the results of another study conducted on 20 septic patients, reported that the non-survivors had a significantly higher median CRP concentration than the survivors [35]

In another study, CRP was significantly elevated in the non survivors (18.52 vs. $13.85-p=0.049$ ) [36]. Besides, Kim and his colleagues also reported that CRP levels were higher in the non-survivors (20.6 vs. $14.7 \mathrm{mg} / \mathrm{dl}-p=0.005)$ [23]. The previous two studies are in line with our study results.

On the contrary, opposite finding was reported by El-Shafie et al., where 31 patients admitted with sepsis to El-Sahel Teaching Hospital, Egypt, and their CRP levels did not show any significant difference between survivors and non-survivors on days 0,2 or 4 [37]

When it comes to leucocytic count in our study cases, there was no statistically significant difference in the total leucocytic count between the survivors and non-survivors ( $p=0.142$ ).

In the study conducted by Kim et al., leucocytic count did not differ significantly between the two groups although it was higher in the non survivors (13.8 vs. $17.1-p=0.211)$ [23]. The same finding was also reported by Choi et al., who reported that leucocytic count was not different between the two groups (7.223 vs. $4.633-p=0.171)$ [36].

As regard platelet count in our study, the platelets count was statistically significantly higher in the non-survivors groups as compared to the survivors $(p<0.05)$.
Orak et al., reported results similar to ours. Platelet counts were significantly higher in the deceased group (227 vs. $268-p=0.008$ ) [21]. Another study confirmed that finding as platelet number was significantly higher in the non survivors (46.1 vs. $146.6-p<0.001)$ [36]

Another study reported that platelet number was not significantly different between survivors and non-survivors $(p=0.44)$ [18]

In the current study, there was significantly elevated lactate levels in the non-survivor group $(p<0.001)$.

Another recent study reported that lactic acid was significantly elevated in the non-survivors $(p=0.0009)$. Serum lactate was 2.3 and $3.3 \mathrm{mmol} / \mathrm{L}$ in survivors and non-survivors groups respectively [19].

Another study confirmed the same finding as serum lactate was significantly elevated in the nonsurvivors $(8.1 \mathrm{mmol} / \mathrm{L})$, compared to survivors $(2.45 \mathrm{mmol} / \mathrm{L})(p<0.001)[36]$

In the current study, higher creatinine levels was present in the non-survivors $(1.96 \pm 0.65 \mathrm{vs}$ $0.73 \pm 0.20 \mathrm{mg} / \mathrm{dl}-p<0.001)$. This agrees with the results of Vardon-Bounes et al., who stated that non-survivors were having significantly higher creatinine levels (148 vs. $115 \mathrm{mmol} / \mathrm{dl}-p<0.0001)$ [19].

On the other hand, another study did not report a difference in creatinine levels between the two groups $(1.4 \mathrm{mg} / \mathrm{dl}$ for both groups $-p=0.835)$ [24] This disagrees with our study results.

Arterial blood gas analysis in this study revealed that $\mathrm{PH}$ was significantly lower in the non-survivors (7.31 vs. $7.35-p=0.046$ ). Other parameters of blood gas analysis $\left(\mathrm{CO}_{2}\right.$ and $\left.\mathrm{HCO}_{3}\right)$ did not differ between the study groups $(p>0.05)$.

Another study also reported that finding. $\mathrm{PH}$ was 7.37 in non-survivors, while it was 7.43 in survivors $(p=0.01)$. However, bicarbonate level did not differ between the two groups ( $p=0.093)$ [23].

Another study also confirmed that $\mathrm{PH}$ levels were significantly decreased in non-survivors $(p=0.0022)$. PH was 7.28 in non-survivors, while it 7.35 in survivors [19]

In the current study, serum potassium was significantly lower in the non-survivors (4.2 vs. 4.9 $-p=0.001)$. However, the mean value of both groups was in the normal limits. 
Another study found no significant difference between potassium levels in survivors and nonsurvivors $(p=0.759)$ [24]

Regarding length of hospital stay in our study, it was evident that it was significantly longer in the non-survivors $(p<0.001)$.

In another study, the length of hospital stay was significantly longer in non-survivors $(p=0.015)$. The mean period of hospital stay was 22.6 in nonsurvivors vs. 15.6 days in survivors [24]. This confirms our study results.

In the current study, the best cutoff point of APACHE II to predict mortality was $>17$ with $84.6 \%$ sensitivity and $64.5 \%$ specificity, $78.8 \%$ PPV and $86.4 \%$ NPV and $82.2 \%$ accuracy.

Bhadade et al., has demonstrated that the area under the ROC curves for APACHE II in predicting mortality in ICU septic patients was (0.835) [38].

It was primarily designed to predict mortality and identify low-risk patients potentially suitable for ambulatory management and has been widely utilized in patients with CAP [39]. The CURB65 score has been extensively validated and performed similarly to the PSI score in predicting 30-day mortality of CAP patients, although previous study revealed that CURB65 may be more suitable for identifying high-risk patients [40].

The simplicity of calculation of CURB65 demonstrated superiority over other complex severity scores utilized in crowded emergency rooms. Furthermore, the CRB65 score, which does not require a blood urea level, is more suitable for use in grossroots hospitals.

In the current study, CURB-65 score was statistically significantly higher in the non-survivors as compared with the survivors $(1.79 \pm 1.26$ and $0.65 \pm 0.43$ respectively) $(p<0.001)$. Moreover, in our study, the cutoff point of Curb-65 score to differentiate between non-survivors from survivors was $>2$ with $59 \%$ sensitivity and $92.3 \%$ specificity.

Unfortunately, no much data is available to describe the prognostic ability of CURB65 in patients with sepsis, as the score was originally developed to assess the prognosis in pneumonia patients.

Yet, our results came in agreement with Zhou et al., who reported that the CURB-65 was significantly higher in the death group, the ICU admission group, the mechanical ventilation group, and the vasopressors use group $(p<0.05)$ [41]
This also came in accordance with Zhang et al., who showed that there were significant differences in CURB-65 score $(p<0.001)$ between ICU and non-ICU admission groups [42]

Our results also agreed with Tokioka et al., who showed that CURB-65 scores was significantly higher among ICU than non-ICU admissions $(p<0.001)[43]$.

This study has some limitations. All the patients included in this study were enrolled in a single medical center, leading to limitations in the generalizability of the results. In this study, we could not evaluate the effect of renal dysfunction and hypoxemia on MPV elevations. Finally, the relatively small sample size we included is a major limitation of this study.

\section{Conclusion:}

Sepsis is a life threating condition and is one of the leading causes of death. Mortality was reported in $55.7 \%$ of patients by the end of the study period. APACHE II was predicting mortality with $84.6 \%$ sensitivity and $64.5 \%$ specificity, $78.8 \%$ PPV \& $86.4 \%$ NPV and $82.2 \%$ accuracy. The length of hospital stay was significantly longer in nonsurvivor group. CURB-65 was statically significantly higher in the non-survivors as compared with the survivors with 59\% sensitivity and $92.3 \%$ specificity but no much data available to describe prognostic ability of CURB-65 in-patient with sepsis as in pneumonia patients.

\section{References}

1- RHODES A., EVANS L.E., ALHAZZANI W., LEVY M.M., ANTONELLI M., FERRER R., KUMAR A., et al.: Surviving sepsis campaign: International guidelines for management of sepsis and septic shock: 2016. Crit Care Med., 45 (3): 486-552, 2017.

2- SEYMOUR C.W., LIU V.X., IWASHYNA T.J., BRUNKHORST F.M., REA T.D., SCHERAG A., RUBENFELD G., et al.: Assessment of Clinical Criteria for Sepsis: For the Third International Consensus Definitions for Sepsis and Septic Shock (Sepsis-3): JAMA, 315 (8): 762-774, 2016.

4- VINCENT J.L. and de CARVALHO F.B.: Severity of illness. Paper presented at the Seminars in respiratory and Critical Care Medicine, 2010.

5- RICHARDS G., LEVY H., LATERRE P.F., FELDMAN C., WOODWARD B., BATES B.M., et al.: CURB-65, PSI, and APACHE II to assess mortality risk in patients with severe sepsis and community acquired pneumonia in PROWESS. J. Intensive Care Med., 26: 34-40, 2011.

6- LIM W., VAN DER EERDEN M., LAING R., BOERSMA W., KARALUS N., TOWN G., et al.: Defining community acquired pneumonia severity on presentation to hospital: An international derivation and validation study. Thorax, 58 (5): 377-382, 2003. 
7- SINGER M., DEUTSCHMAN C.S., SEYMOUR C.W., et al.: The third international consensus definitions for sepsis and septic shock (Sepsis-3): JAMA, 315 (8): 801810,2016

8- LEVY M.M., EVANS L.E. and RHODES A.: The surviving sepsis campaign bundle: 2018 update. Intensive Care Medicine, 44 (6): 925-928, 2018.

9- KUPAS D.F., MELNYCHUK E.M. and YOUNG A.J.: Glasgow coma scale motor component ("patient does not follow commands") performs similarly to total glasgow coma scale in predicting severe injury in trauma patients. Annals of Emergency Medicine, 68 (6): 744-750. e743, 2016.

10- SHAIKH M.A. and YADAVALLI D.R.: Red cell distribution width as a prognostic marker in severe sepsis and septic shock. International Journal of Advances in Medicine, 4 (3): 750, 2017.

11-ANGUS D.C. and VANDERPOLL T.: Severe sepsis and septic shock. N. Engl. J. Med., 369: 840-851, 2013.

12- AFESSA B., KEEGAN M.T., MOHAMMAD Z., FINKIELMAN J.D. and PETERS S.G.: Identifying potentially ineffective care in the sickest critically ill patients on the third ICU day. Chest, 126 (6): 1905-1909, 2004.

13- ANNANE D., BELLISSANT E. and CAVAILLON J.M. Septic shock. The Lancet, 365 (9453): 63-78, 2005.

14- MARSHALL J. and REINHART K.: International sepsis forum. Biomarkers of sepsis. Crit Care Med., 37 (7): 2290-2298, 2009.

15- BEG ENEN M., DURAK V.A., AKALiN H. and ARMAGEAN E.: Evaluation of prognostic value of MEDS MEWS, and CURB-65 criteria and sepsis I and sepsis III criteria in patients with community-acquired infection in emergency department. Hong Kong Journal of Emergency Medicine, 27 (5): 277-285, 2019.

16- HASSAN E.A., ABDEL REHIM A.S., AHMED A.O., ABDULLAHTIF $H$. and ATTIA A.: Clinical value of presepsin in comparison to hsCRP as a monitoring and early prognostic marker for sepsis in critically ill patients. Medicina, 55 (2): 36, 2019.

17- AMER H.A., GHAREEB H., LOTFY N.M., EL-AZIZI N.O. and MAHMOUD A.M.: Presepsin a diagnostic marker for sepsis in intensive care unit patients. Egypt J. Immunol., 23 (2): 109-118, 2016.

18- GAO Y., LI Y., YU X., GUO S., JI X., SUN T., LAN C., LAVERGNE V., GHANNOUM M. and LI L.: The impact of various platelet indices as prognostic markers of septic shock. PLoS One, 9 (8): e103761, 2014.

19- VARDON-BOUNES F., GRATACAP M.-P., GROYER S., RUIZ S., GEORGES B., SEGUIN T., GARCIA C., PAYRASTRE B., CONIL J.M. and MINVILLE V.: Kinetics of mean platelet volume predicts mortality in patients with septic shock. PLoS One, 14 (10): e0223553, 2019.

20- KIM S., LEE K., KIM I., JUNG S. and KIM M.-J.: Red cell distribution width and early mortality in elderly patients with severe sepsis and septic shock. Clinical and Experimental Emergency Medicine, 2 (3): 155, 2015 b.

21- ORAK M., KARAKOÇ Y., ÜSTÜNDAG M., YILDIRIM Y., CELEN M. and GÜLOGLU C.: An investigation of the effects of the mean platelet volume, platelet distribution width, platelet/lymphocyte ratio, and platelet counts on mortality in patents with sepsis who applied to the emergency department. Nigerian journal of clinical practice, 21 (5): 667-671, 2018.

22- ANGUS D.C., LINDE-ZWIRBLE W.T., LIDICKER J., CLERMONT G., CARCILLO J. and PINSKY M.R.: Epidemiology of severe sepsis in the United States: analysis of incidence, outcome, and associated costs of care. Read Online: Critical Care Medicine| Society of Critical Care Medicine, 29 (7): 1303-1310, 2001.

23- KIM C.H., KIM S.J., LEE M.J., KWON Y.E., KIM Y.L., PARK K.S., RYU H.J., PARK J.T., HAN S.H. and YOO T.H.: An increase in mean platelet volume from baseline is associated with mortality in patients with severe sepsis or septic shock. PLoS One, 10 (3): e0119437, 2015a.

24- LEE J.H., PARK M., HAN S., HWANG J.J., PARK S.H. and PARK S.Y.: An increase in mean platelet volume during admission can predict the prognoses of patients with pneumonia in the intensive care unit: A retrospective study. PLoS One, 13 (12): e0208715, 2018.

25- JANDIAL A., KUMAR S., BHALLA A., SHARMA N., VARMA N. and VARMA S.: Elevated red cell distribution width as a prognostic marker in severe sepsis: A prospective observational study. Indian journal of critical care medicine: Peer-reviewed, official publication of Indian Society of Critical Care Medicine, 21 (9): 552, 2017.

26- SAAD S., MOHAMED N., MOGHAZY A., ELLABBAN G. and EL-KAMASH S.: Venous glucose, serum lactate and base deficit as biochemical predictors of mortality in patients with polytrauma. Ulus Travma Acil Cerrahi Derg, 22 (1): 29-33, 2016.

27- SALEM A.M., SALEM A.E. and AL KHOLY A.F.: Prediction of Outcome of Sepsis at Surgical ICU: A Prospective Multi-Center Prospective Study, 1-8, 2019.

28- JIANG L., FENG B., GAO D. and ZHANG Y.: Plasma concentrations of copeptin, C-reactive protein and procalcitonin are positively correlated with APACHE II scores in patients with sepsis. Journal of International Medical Research, 43 (2): 188-195, 2015.

29- HUANG L., LI J., HAN Y., ZHAO S., ZHENG Y., SUI F., XIN X., MA W., JIANG Y. and YAO Y.: Serum calprotectin expression as a diagnostic marker for sepsis in postoperative intensive care unit patients. Journal of Interferon \& Cytokine Research, 36 (10): 607-616, 2016.

30- QIU Z., SHEN K., SHU M., XU D., DENG X. and CHEN D.: Value of Hepcidin as a diagnostic biomarker of sepsis in critically ill adults. Zhonghua wei zhong bing ji jiu yi xue, 30 (7): 652-657, 2018.

31- OGURA T., NAKAMURA Y., TAKAHASHI K., NISHIDA K., KOBASHI D. and MATSUI S.: Treatment of patients with sepsis in a closed intensive care unit is associated with improved survival: A nationwide observational study in Japan. Journal of Intensive Care, 6 (1): 57, 2018.

32- RUMINSKI C.M., CLARK M.T., LAKE D.E., KITZMILLER R.R., KEIM-MALPASS J., ROBERTSON M.P., SIMONS T.R., MOORMAN J.R. and CALLAND J.F.: Impact of predictive analytics based on continuous cardiorespiratory monitoring in a surgical and trauma intensive care unit. Journal of clinical monitoring and computing, 33 (4): 703-711, 2019 
33- WACKER C., PRKNO A., BRUNKHORST F.M. and SCHLATTMANN P.: Procalcitonin as a diagnostic marker for sepsis: A systematic review and meta-analysis. The Lancet Infectious Diseases, 13 (5): 426-435, 2013.

34- CREAMER A.W., KENT A.E. and ALBUR M.: Procalcitonin in respiratory disease: use as a biomarker for diagnosis and guiding antibiotic therapy. Breathe, 15 (4): 296304, 2019.

35- PIECHOTA M., BANACH M., IRZMAN'SKI R., MISZ TAL M., RYSZ J., BARYLSKI M., PIECHOTA-URBAN'SKA M., KOWALSKI J. and PAWLICKI L.: N-terminal brain natriuretic propeptide levels correlate with procalcitonin and C-reactive protein levels in septic patients. Cellular \& Molecular Biology Letters, 12 (2): 162-175, 2007.

36- CHOI S.J., HA E.J., JHANG W.K. and PARK S.J.: Platelet Indices as Predictive Markers of Prognosis in Pediatric Septic Shock Patients. Iranian Journal of Pediatrics, 27 (3), 2017.

37- EL-SHAFIE M.E.-.S, TAEMA K.M., EL-HALLAG M.M and KANDEEL A.M.A.: Role of presepsin compared to C-reactive protein in sepsis diagnosis and prognostication. The Egyptian Journal of Critical Care Medicine, 5 (1): 1-12, 2017.

38- BHADADE R., DeSOUZA R., HARDE M. and SRIDHAR B.: Microalbuminuria: a biomarker of sepsis and efficacy of treatment in patients admitted to a medical intensive care unit of a tertiary referral center. Journal of postgraduate Medicine, 60 (2): 145, 2014.

39- CHEN Y.X. and LI C.S.: Lactate on emergency department arrival as a predictor of mortality and site-of-care in pneumonia patients: A cohort study. Thorax, 70 (5): 404410,2015

40- CHALMERS J.D., SINGANAYAGAM A., AKRAM A.R., et al.: Severity assessment tools for predicting mortality in hospitalised patients with community-acquired pneumonia. Systematic review and meta-analysis. Thorax, 65 (10): 878-883, 2010.

41- ZHOU H., LAN T. and GUO S.: Prognostic Prediction Value of qSOFA, SOFA, and Admission Lactate in Septic Patients with Community-Acquired Pneumonia in Emergency Department. Emergency Medicine International, 2020 .

42- ZHANG X., LIU B., LIU Y., MA L. and ZENG H.: Efficacy of the quick sequential organ failure assessment for predicting clinical outcomes among communityacquired pneumonia patients presenting in the emergency department. BMC Infectious Diseases, 20, 1-8, 2020.

43- TOKIOKA F., OKAMOTO H., YAMAZAKI A., ITOU A. and ISHIDA T.: The prognostic performance of qSOFA for community-acquired pneumonia. Journal of Intensive Care, 6 (1): 46, 2018 


\section{المقارنة بين معايير كورب ـ 70 ومعايير أباتشى الثانى

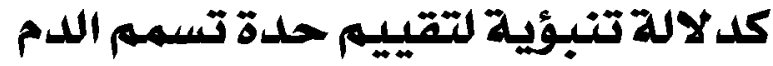

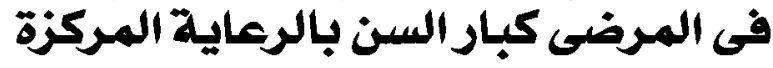

تسمم الدم حالة مهددة للحياة وهى أحد الأسباب الرئيسية للوفاة، وقد تم نشر تعريفات جديدة لتسمم الدم والصدمة التسممية (تسمم الدم-

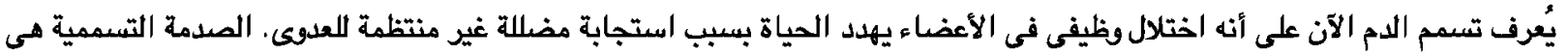

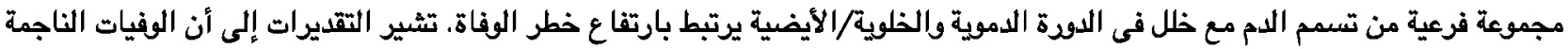

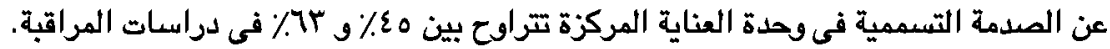

يتم استخدام أنظمة تسجيل تقييم الخطورة لفرذ المرضى الذين يعانون من تسمم الدم وذلك لمعاعدة الطبيب في تقرير ما إذا كان العلاج

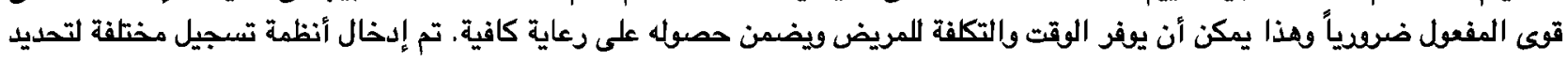
شدة المرض والتشخيص المرضى المقبولين فى وحدة العناية المركزة.

الهدف من دراستا: هو مقارية تقيبم الشدة بين نظامى تسجيل، وهما علم وظائف الأعضاء الحاد، وتقيبم العمر والصحة المزمنة الثانى أباتشى الثانى وكوب-70.

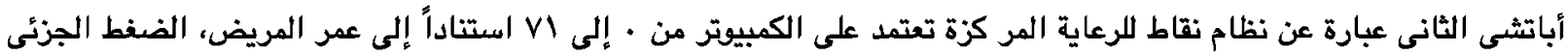

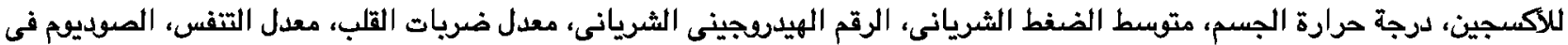

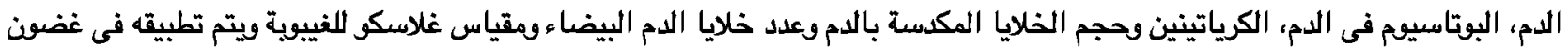

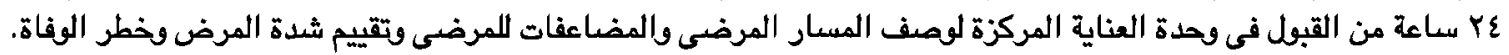

كلما كان نقاط أباتشى الثانى أعلى فهذا يعكس شدة المرض وزيادة معدل الوفيات لاىى مرضى وحدة العناية المركزة المصابين بتسمم الدم.

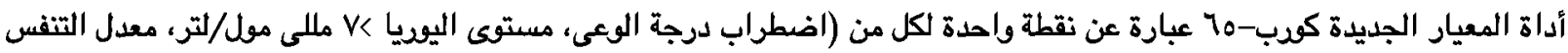

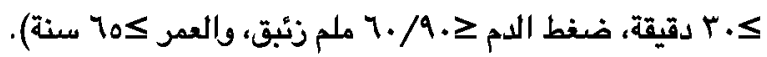

يمكن لـ كوب-

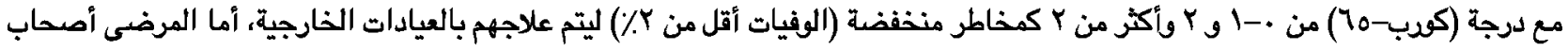

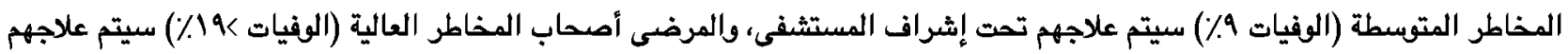

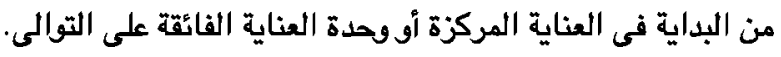

